\title{
Maternal and foetal outcome in second stage caesarean section: a prospective study
}

\section{Shuchi Sharma*, Poojan Dogra, Reena Sharma, Suraj Bhardwaj}

\author{
Department of Obstetrics and Gynecology, SLBS Government Medical College, Mandi, Himachal Pradesh, India
}

Received: 31 January 2021

Revised: 10 March 2021

Accepted: 11 March 2021

\author{
*Correspondence: \\ Dr. Shuchi Sharma, \\ E-mail: sharma.shuchi@yahoo.com
}

Copyright: ( ) the author(s), publisher and licensee Medip Academy. This is an open-access article distributed under the terms of the Creative Commons Attribution Non-Commercial License, which permits unrestricted non-commercial use, distribution, and reproduction in any medium, provided the original work is properly cited.

\begin{abstract}
Background: Caesarean section is the most commonly performed abdominal operation in women all over the world. Caesarean sections during the second stage labour accounts for approximately one fourth of all primary caesareans. Caesarean section at full cervical dilatation is technically difficult and is associated with increased trauma to the lower uterine segment and adjacent structures, as well as increased haemorrhage and infection. Aims and objectives were to determine the indications, maternal and foetal morbidity associated with caesarean section in the second stage of labour.

Methods: This prospective study included consecutive 50 cases of caesarean section deliveries conducted in second stage of labor for singleton live pregnancies at term. The data collected in the study was analyzed in terms of maternal demographics, indications of caesarean section, intra-operative and postoperative complications and neonatal outcomes.

Results: In our series of 50 deliveries, arrest of descent of fetal head due to malposition was the most common indication of caesarean section accounting for $74 \%$ and average procedure time was $45-70$ minutes. PPH (62\%) was the most common complication. Bladder injury was found in $14 \%$ cases. Neonatal outcome variables like APGAR<3 at 5 minutes, respiratory distress and neonatal death were observed in 7, 26 and 2 deliveries respectively.

Conclusions: Women undergoing cesarean section in second stage of labour are associated with increased maternal and fetal morbidity. They require special care and hence operation should ideally be performed and supervised by an experienced obstetrician. A proper judgement is required to take a decision for caesarean section at full cervical dilatation.
\end{abstract}

Keywords: Caesarean section, Cervical dilatation, Maternal and fetal outcome, PPH, Uterine tear

\section{INTRODUCTION}

Caesarean section is the most commonly performed abdominal operation in women all over the world. Incidence of caesarean section is increasing for greater safety of the baby, less pelvic floor trauma, avoidance of labour pains and convenience. In Medical colleges and teaching hospitals in India, the overall rate of caesarean deliveries is $24.4 \%$. Incidence of second stage caesarean section has increased from $0.9 \%$ to $2.2 \% .^{1}$ Caesarean section can be performed before onset of labour or during first or second stage of labour. Second stage of labour starts with full cervical dilatation and ends with delivery of the foetus. In prolonged second stage, the interventions to facilitate delivery of the fetus are either assisted instrumental vaginal delivery or caesarean section. ${ }^{2}$ Worldwide, $10-20 \%$ of deliveries require some form of interventions and this intervention is frequently caesarean section. The incidence of operative vaginal deliveries has decreased with a corresponding increase in caesarean section deliveries in the second stage of labor. ${ }^{3}$

Nowadays, decline in the use of instrumental delivery is due to lack of training, no supervision of junior staff in 
decision-making and loss of technical skill associated with difficult-instrumental delivery. Caesarean section at full cervical dilatation with an impacted fetal head can be technically difficult and associated with postpartum hemorrhage, bladder injury, extended uterine tear leading to broad ligament haematoma, infection and longer hospital stay. ${ }^{4}$ The second stage caesarean section (CS) cause the fetal distress due to intra-operative fetal hypoxia caused by strong uterine contraction, deeply impacted fetal head and longer duration of second stage of labor. Although second stage CS may be necessary, many of them could be avoided by the attendance of skilled senior obstetrician and implementation of proper instrumental delivery. 3,4

The increasing trend of caesarean section at second stage is of major concern in modern obstetrics. Hence this study was conducted to know the indications of second stage cesarean sections in Department of Obstetrics and Gynecology and to assess maternal and neonatal outcome in second stage caesarean section.

\section{Aims and objectives}

To determine the indications, maternal and foetal morbidity associated with caesarean section in the second stage of labour.

\section{METHODS}

This prospective study was conducted in SLBS Government Medical College, Mandi, Himachal Pradesh, on 50 consecutive caesarean sections done in second stage of labour between October 2017 and September 2019. Fifty women who underwent second stage CS were analysed in terms of indications for second stage CS, intra-operative and postoperative complications, as well as fetal outcome. Data was collected after getting technical and ethical committee clearance.

\section{Selection criteria}

Age group between 18 to 40 years. Singleton pregnancy irrespective of parity. Period of gestation $>37$ weeks.

\section{Exclusion criteria}

Pregnancies with history of pre-existing medical illness. Pregnancies with major fetal abnormalities and fetal growth restriction. Multiple pregnancy. Preterm.

Type of anaesthesia and the operative technique were same in all the patients. The surgical technique of caesarean section was standardized. The data was collected in preformed proforma and written and informed consent was taken. All the data collected was pooled together and recorded and entered in master chart. Data analysis was done with the help of computer software MS Excel and SPSS version 17 for windows.
The maternal composite outcome in our study included one or more of the following: indications for second stage caesarean sections, intraoperative complications including uterine artery injury, extension of uterine incision, bladder injury, cervical laceration or requirement of hysterectomy, PPH, need for blood transfusion, duration of surgery, wound infection, duration of hospital stay, puerperal sepsis and maternal death.

Indicators of neonatal outcome in our study were APGAR score of newborns at 5 minutes, respiratory distress, admission to NICU and resuscitation and death. The duration of surgery was measured and was taken as the time elapsed between skin incision and skin closure. Extension of primary uterine incision is defined as any uterine wall defect, either laterally into the uterine vasculature, or vertically into the cervix or a contractile uterus that required additional steps to repair. $\mathrm{PPH}$ is defined as estimated blood loss $>1000 \mathrm{ml}$. Post-partum endometritis refers to infection of decidua. It is defined as persistent postpartum temperature $>38.5^{\circ} \mathrm{C}$ with malodorous vaginal discharge and uterine tenderness on bimanual examination and no other pelvic infection. Mother and baby were followed till discharge. Any complications to the mother and baby which developed during their hospital stay were also noted

\section{RESULTS}

Total number of deliveries during the study period of 2 years was 7108. 2032 were delivered by caesarean section. Out of these our study was conducted on 50 consecutive caesarean sections performed in second stage. Among these 36 (72\%) were primigravida and 14 (28\%) were multigravida pregnancies. $6 \%$ of them were less than 20 years of age, $60 \%$ were in the age group of 20-25 years, $26 \%$ were between $26-30$ years and only $8 \%$ were above 30 years.

Table 1: Maternal demographic details.

\begin{tabular}{|c|c|c|c|}
\hline Variables & & $\begin{array}{l}\text { Number, } \\
\mathrm{N}=\mathbf{5 0}\end{array}$ & Percentage \\
\hline \multirow{4}{*}{$\begin{array}{l}\text { Age } \\
\text { distribution }\end{array}$} & $<20$ years & 3 & 6 \\
\hline & $20-25$ years & 30 & 60 \\
\hline & $26-30$ years & 13 & 26 \\
\hline & $>30$ years & 4 & 8 \\
\hline \multirow{2}{*}{$\begin{array}{l}\text { Parity } \\
\text { distribution }\end{array}$} & Primi gravida & 36 & 72 \\
\hline & Multigravida & 14 & 28 \\
\hline \multirow{4}{*}{$\begin{array}{l}\text { Gestational } \\
\text { age }\end{array}$} & 37-38 weeks & 19 & 38 \\
\hline & 38-39 weeks & 21 & 42 \\
\hline & $39-40$ weeks & 7 & 14 \\
\hline & $>40$ weeks & 3 & 6 \\
\hline
\end{tabular}

The gestational age was between $37-38$ weeks in $38 \%$ deliveries, 38-39 weeks in 42\%, 39-40 weeks in 14\% and more than 40 weeks in $6 \%$ deliveries. The demographic data is presented in Table 1. 
Table 2: Indications for surgery.

\begin{tabular}{|lll|}
\hline Indications & Number, $\mathbf{n = 5 0}$ & Percentage \\
\hline $\begin{array}{l}\text { Arrest of descent } \\
\text { (malposition) }\end{array}$ & 37 & 74 \\
\hline $\begin{array}{l}\text { Arrest of descent } \\
\text { (CPD) }\end{array}$ & 11 & 22 \\
\hline Failed vacuum & 2 & 4 \\
\hline
\end{tabular}

Arrest of descent due to malposition was the most common indication for surgery in second stage in 37 cases (74\%) followed by CPD in 11 cases $(22 \%)$. Failed vacuum delivery accounted for 2 cases (Table 2). The most common complication in second stage CS was PPH in 31 cases $(62 \%)$. Out of these blood transfusion was required in 20 cases $(40 \%)$. Lateral uterine tear occurred in 9 cases $(18 \%)$. There were no cases of bowel injury while bladder injury was reported in 7 cases $(14 \%)$. Post-operative wound infection was seen 8 cases $(16 \%)$ and post-operative fever was seen in 15 cases $(30 \%)$ (Table 3).

\section{Table 3: Incidence of intra operative and postoperative complications.}

\begin{tabular}{|lll|}
\hline Variables & $\begin{array}{l}\text { Number, } \\
\text { N=50 }\end{array}$ & Percentage \\
\hline PPH & 16 & 32 \\
\hline Need for blood transfusion & 10 & 20 \\
\hline Lateral uterine tear & 9 & 18 \\
\hline Bladder injury & 7 & 14 \\
\hline Post op wound infection & 8 & 16 \\
\hline Post op fever & 15 & 30 \\
\hline
\end{tabular}

The mean operative time required from incision to closure was 61.3 minutes and mean length of hospital stay was 6.8 days (Table 4). There were no cases of maternal deaths reported.

Table 4: Operative time and length of hospital stay.

\begin{tabular}{|lll|}
\hline Variable & Range & Mean \\
\hline Operative time & $45-70$ minutes & 61.3 minutes \\
\hline Length of hospital stay & $5-15$ days & 6.8 days \\
\hline
\end{tabular}

APGAR $<3$ at 5 min was seen in 7 cases (14\%). Respiratory distress was seen in 26 cases (52\%). Need for admission and resuscitation was needed in all the neonates who had respiratory distress. There were 2 neonatal deaths $(4 \%)$ reported (Table 5).

Table 5: Neonatal complications.

\begin{tabular}{|lll|}
\hline Variables & Number, $\mathbf{n = 5 0}$ & Percentage \\
\hline $\mathbf{5}$ minute APGAR $<3$ & 7 & 14 \\
\hline Respiratory distress & 26 & 52 \\
\hline Need for resuscitation & 26 & 52 \\
\hline Neonatal death & 2 & 4 \\
\hline
\end{tabular}

\section{DISCUSSION}

The rates of caesarean sections have risen steadily in the past two decades and may be associated with a disproportionate rise in second stage of caesarean sections. Increasing medical litigations in current obstetrics and concerns over neonatal and maternal morbidity associated with difficult or failed instrumental delivery may contribute to this trend. Majority of women were in the age group 20-25 years (58\%) which was comparable to study by Landon et al in which $61 \%$ women were in age group 21-30 years. ${ }^{5}$ The incidence of second stage caesarean sections was more in primigravida $(72 \%)$ than multigravida $(28 \%)$ in the present study; this observation was similar to study by Babre et al. ${ }^{6}$ The increased frequency of second stage caesareans in primigravidae could be due to cephalopelvic disproportion, rigid perineum and lack of experience of previous labor. Majority of cases were of gestational age 38-39 weeks (42\%). In our study arrest of descent of fetal head due to malposition (74\%) was the most common indication for caesarean sections in 2 nd stage of labour.

Caesarean section in the second stage of labor is technically difficult and was 2.6 times likely to have intraoperative traumatic complications. The difficulty in delivering the fetal head arises because of lack of space between the bony pelvis, pelvic soft tissues and the fetal head and the degree that the head has moulded into the pelvis. ${ }^{5,6}$

Intraoperative disengagement of the fetal head continues to pose a challenge to obstetricians. The incidence of uterine incision extension in second stage caesarean sections may be as high as $30 \%$. It is thought that when performing caesarean sections at full dilatation, a higher incision in the uterus may be necessary. A standard incision may risk incising the bladder or the vagina, or may affect the integrity of the cervix. Lower-segment incisions may also be at increased risk of tearing and be more difficult to repair. ${ }^{7}$ In our study we experienced incidence of uterine tear in $9(18 \%)$ deliveries, which were managed intraoperatively by repairing techniques.

Development of uterine atony and requirement of uterine artery ligation in the case of severe hemorrhage are also found to be more frequent in caesarean section performed in the second stage of labor and can be due to the prolonged labor resulting in uterine inertia. In our study $32 \%$ cases experienced PPH whereas study conducted by Baloch et al observed PPH in only $12.5 \%{ }^{8}$

As compared to Asicioglu et al which revealed a significant increase in mean blood loss in second stage cesarean sections, in our study $20 \%$ cases required blood transfusion. ${ }^{9}$ Studies have reported pelvic floor trauma, particularly bladder and bowel problems. In our study, $14 \%$ patients had bladder injury but we didn't encounter any bowel injury. 
Cebekulu et al from Johannesburg, South Africa, reporting on 39 cases and 39 controls, found that secondstage caesarean section was associated with more postoperative fever. ${ }^{10}$ In present study post-operative fever was noted in $30 \%$ and postoperative wound infection in $16 \%$ of cases who delivered by second stage caesarean section and contributing to relatively longer duration of stay in the hospital whereas in the study by Baloch et al wound infection was present in $8.33 \%$ cases. $^{8}$

In various studies it has been quoted that duration of hospital stay for patients in second stage caesarean section is increased. In the study by Seal et al, the mean length of stay in the hospital after delivery was higher in second stage caesarean section i.e. 6.4 days. ${ }^{11}$ In our study mean length of hospital stay was 6.8 days which was comparable to study by Seal et al. Ojeme et al found that women who had cesarean deliveries performed in second stage had longer operative time, greater blood loss, more cases of intraoperative trauma, primary $\mathrm{PPH}$, blood transfusion, re look laparotomy, hysterectomy, post-partum pyrexia wound infection and a longer hospital stay. ${ }^{12}$ There was no case of maternal mortality in our study.

A recent study by Das et al demonstrated a statistically significant increase in admission to NICU, septicaemia, low 5 minute Apgar $(<3)$ and neonatal trauma. ${ }^{13}$ In our study APGAR score below 3 at 5 minutes was found in $14 \%$ after second stage caesarean sections. There were 26 cases who required resuscitation procedures and NICU admission for respiratory distress. There was $4 \%$ neonatal mortality in our study. The unfavorable neonatal outcomes are probably due to prolonged labour which leads to hypoxia. ${ }^{14,15}$

A recent study by Radha et al demonstrated a statistically significant increase in birth asphyxia, admission to the neonatal intensive care unit, sepsis, seizures, need for ventilation and neonatal death. ${ }^{16}$

The small sample size, short follow up period, not assessing the instrumental deliveries which could prevent second stage caesarean sections and effect of second stage caesarean sections on subsequent pregnancies were limitations of our study.

\section{CONCLUSION}

Caesarean sections during the second stage are increasing in prevalence. Caesarean section at full cervical dilatation is associated with increased risk of adverse outcome for both mother and foetus. Maternal risks of second stage caesareans include greater risk of $\mathrm{PPH}$, extension tears of the uterine angle and longer hospital stay. Caesarean delivery performed during the second stage of labour increases the incidence of foetal respiratory distress, admission to the neonatal intensive care unit and foetal death due to foetal head impaction into the maternal pelvis and prolonged second stage labour. Hence it is recommended that second stage caesarean should ideally performed and supervised by an experienced obstetrician. Timely decision for caesarean section should be taken especially when risk factors for failure to progress are present.

For decision making, the involvement of senior obstetrician is desired for safe trial of vaginal delivery or CS. Alarming the neonatologist beforehand are recommended in all second stage deliveries. The modern management of the second stage of labour will have to consider the risks and benefits of the instrumental vaginal delivery versus caesarean section.

\section{Funding: No funding sources}

Conflict of interest: None declared

Ethical approval: The study was approved by the Institutional Ethics Committee

\section{REFERENCES}

1. Kambo I, Bedi N, Dhillon BS, Saxena NC. A critical appraisal of caesarean section rates at teaching hospitals in India. Int $\mathbf{J}$ Gynaecol Obstet. 2002;79:151-8.

2. Thomas J, Paranjothy S. Royal College of Obstetricians and Gynaecologists Clinical Effectiveness Support Unit. The national sentinel caesarean section audit report. London: RCOG Press; 2001.

3. Vousden N, Cargill Z, Briley A, Tydeman G, Shennan AH. Caesarean section at full dilatation: incidence, impact and current management. Obstet Gynaecol. 2014;16(3):199-205.

4. Allen VM, O'Connell CM, Liston RM. Maternal morbidity associated with cesarean delivery without labor compared with spontaneous onset of labor at term. Obstet Gynecol. 2003;102:477-82.

5. Landon MB, Hauth JC, Leveno KJ, Spong CY, Leindecker S, Varner MW, et al. Maternal and perinatal outcomes associated with a trial of labor after prior cesarean delivery. $\mathrm{N}$ Engl $\mathrm{J}$ Med. 2004;351(25):2581-9.

6. Babre VM, Bendre KR, Niyogi G. Review of caesarean sections at full dilatation. Int $\mathrm{J}$ Reprod Contracept Obstet Gynecol. 2017;6(6):2491-3.

7. Unterscheider J, McMenamin M, Cullinane F. Rising rates of caesarean deliveries at full cervical dilatation: a concerning trend. Eur J Obstet Gynecol Reprod Biol. 2011;157(2):141-4.

8. Baloch S, Khaskheli M, Khushk IA, Sheeba A. Frequency of second stage intervention and its outcome in relation with instrumental vaginal delivery versus caesarean section. J Ayub Med Coll Abbottabad. 2008;20(1):87-90.

9. Asicioglu O, Gungorduk K, Yildirim G, Asicioglu BB, Gungorduk OC, Ark C. Second-stage versus first-stage caesarean delivery: comparison of 
maternal and perinatal outcomes. J Obstet Gynaecol. 2014a;34:598-604.

10. Cebekulu L, Buchmann EJ. Complications associated with caesarean section in the second stage of labour. Int J Gynaecol Obstet. 2006;95:110-4.

11. Seal SL, Kamilya G, Mukherji J, Bhattacharyya SK, Alok D, Hazra A. Outcome in second- versus first stage caesarean delivery in a teaching institution in Eastern India. Am J Perinatol. 2010;27:06,

12. Selo-Ojeme D, Sathiyathasan S, Fayyaz M. Caesarean delivery at full cervical dilatation versus caesarean delivery in the first stage of labour: comparison of maternal and perinatal morbidity. Archs Gynecol Obstet. 2008;278:245-9.

13. Das S, Sarkar SK. Fetomaternal outcome in second versus First stage caesarean delivery in a tertiary rural medical college. IOSR J Dent Med Sci. 2014;13(12):28-30.
14. Allen VM, O'Connell CM, Baskett TF. Maternal and perinatal morbidity of caesarean delivery at full cervical dilatation compared with caesarean delivery in the first stage of labour. BJOG. 2005;112(7):98690

15. Murphy DJ, Liebling RE, Verity L, Swingler R, Patel R. Early maternal and neonatal morbidity associated with operative delivery in second stage of labour: a cohort study. Lancet. 2001;358:1203-7.

16. Rhadha P, Tagore S, Rahman MFA, Tee J. Maternal and perinatal morbidity after caesarean delivery at full cervical dilatation. Singapore Med J. 2012;53:655-8.

Cite this article as: Sharma S, Dogra P, Sharma R, Bhardwaj S. Maternal and foetal outcome in second stage caesarean section: a prospective study. Int $\mathbf{J}$ Reprod Contracept Obstet Gynecol 2021;10:1644-8. 